\title{
A legendação visível: da atividade tradutória interlinguística ao ensino de leitura em L1
}

\author{
Ana Cláudia de Souza ${ }^{1}$ \\ Fabiana Staudinger ${ }^{2}$ \\ Silvane Daminelli ${ }^{3}$
}

\begin{abstract}
This article intends to explore the possibilities of including the translation for subtitles in the planning of reading teaching of Portuguese as L1, in circumstances with learning difficulties and low performance of the students. The discussion is based on two researches developed in the scope of translation studies, one dealing with the aspects and parties involved in the subtitling process and its final product and the other focusing on and implementing instructional strategies and instructional procedures of reading teaching based on the text of subtitled foreign films. As a result of the application of the proposed intervention for teaching of Portuguese as L1, reading performance data were significantly higher in the course of the proposed activities with the students, which reveals that subtitled foreign films can play a role not only as a motivational factor to build up readers but also stimulate as an efficient tool for reading teaching.
\end{abstract}

Keywords: Subtitling; Text of subtitled foreign films; Teaching reading; Teaching of L1.

Resumo: Este artigo busca lançar luz a possibilidades de inclusão da tradução para legendas no planejamento de ensino de leitura em língua portuguesa como L1, em contextos de dificuldade de aprendizagem e baixo desempenho dos estudantes. A discussão está embasada em duas pesquisas desenvolvidas no âmbito dos estudos da tradução: uma tratando dos aspectos e agentes envolvidos no processo de legendação e do seu produto final, outra focalizando e implementando estratégias de planejamento e procedimentos instrucionais de ensino de leitura com base em textos fílmicos estrangeiros legendados. Como resultado da aplicação da intervenção proposta para o ensino de português como L1, obtiveram-se dados de desempenho em leitura sensivelmente superiores no decorrer do desenvolvimento das atividades propostas com os estudantes, o que revela que obras fílmicas estrangeiras legendadas podem exercer papel não apenas motivador para a formação de leitores, mas também incitador, como ferramenta eficiente para o ensino de leitura.

Palavras-chave: Legendação; Textos fílmicos estrangeiros legendados; Ensino de leitura; Ensino de L1.

1 Docente do Curso de Letras e do Programa de Pós-Graduação em Linguística da Universidade Federal de Santa Catarina.Email: ana.claudia.souza@ufsc.br

2 Diretora de Missões, Recepções e Eventos da Secretaria Executiva de Assuntos Internacionais do Governo do Estado de Santa Catarina. Email: staudinger.fabiana@gmail.com

3 Docente do Instituto Federal Catarinense - Campus Santa Rosa do Sul. Email: silvane.daminelli@santarosa. ifc.edu.br 
O problema de que trata este artigo é fruto de dois estudos desenvolvidos acerca da legendação: um deles focalizando aspectos da atividade tradutória e do seu entorno, outro tomando para si a tradução já realizada e implementando-a como elemento do texto fílmico em projeto de ensino de leitura em língua portuguesa. A principal questão que se coloca é a seguinte: Em que medida a legendação interlinguística (com todas as suas ressalvas) pode participar de ações e procedimentos de ensino de leitura em primeira língua (L1)? Tal questão se situa para além dos limites de discussão da atividade tradutória e de seus efeitos sobre o público-alvo do texto (normalmente fílmico) final, colocando-se em uma zona de confluência na qual se encontram tradução e ensino de L1 no espaço de sala de aula de Língua Portuguesa com vistas à formação de sujeitos leitores.

O primeiro estudo de que trata este artigo foi desenvolvido, sob a orientação da primeira autora, pela segunda autora deste texto como pesquisa de mestrado em Estudos da Tradução na Universidade Federal de Santa Catarina (UFSC), tendo como um de seus propósitos (aquele que interessa aqui mencionar) discutir a visibilidade da legendação como atividade tradutória aos olhos do espectador e a invisibilidade do legendador, cuja autoria na maior parte dos casos é desbancada, diluída e apagada. O segundo estudo também foi desenvolvido, sob a orientação da primeira autora, nos Estudos da Tradução da UFSC, tratando do doutoramento da terceira autora deste artigo, cujo tema de pesquisa versou sobre o ensino de leitura em língua portuguesa como L1 em contexto de dificuldade de aprendizagem, por meio de obras cinematográficas legendadas. Trata-se de pesquisa de caráter experimental, na qual foi aplicada intervenção pedagógica, em sala de aula, com vistas ao ensino de leitura.

Agradecemos à Prof ${ }^{a}$. Cleci Bevilacqua por ter incitado a organização das ponderações sobre este tema, que vinha figurando como um de nossos objetos de investigação desde o ano de 2008, mas sobre o qual ainda não nos tínhamos aventurado a tratar de modo tão integrativo e extramuros, como o proposto na conferência realizada em abril de 2016, na ocasião da visita da primeira autora à Universidade Federal do Rio Grande do $\mathrm{Sul}$ e aqui retomado e reorganizado com vistas a oferecer ao leitor um relato fundamentado da perspectiva que assumimos acerca da legendação e do seu potencial papel (entre tantos outros) no ensino de leitura em língua portuguesa a estudantes que se encontram em situação de dificuldade de aprendizagem e baixo desempenho escolar.

\section{A legendação: da invisibilidade à visibilidade}

Nesta seção, trataremos da pesquisa de mestrado de Staudinger, desenvolvida entre 2008 e 2010, na UFSC, e intitulada "A (in)visibilidade do tradutor na legendação: a tradução do filme The Woods"4. O propósito deste estudo foi explorar a oportunidade de acesso ao processo de legendação e analisar a invisibilidade do tradutor em uma atividade tradutória que o coloca em evidência. Esse objetivo pôde ser alcançado, uma vez que a autora desta pesquisa de mestrado foi também legendadora da obra supracitada e, por isso, teve acesso a todo o processo tradutório e às versões geradas, incluindo o resultado final, disponível ao grande público.

Há que se considerar que, na legendação de textos audiovisuais, não existe distanciamento temporal e espacial entre língua de partida e língua de chegada para aquele

4 Dissertação disponível em: <http://www.tede.ufsc.br/teses/PGET0089-D.pdf $>$. Acesso em 05 de abril de 2017. 
que recebe a obra, o espectador-leitor, pois o texto verbal de partida, fundamentalmente em forma de áudio, e o texto verbal de chegada, em forma de legenda escrita, são apresentados simultaneamente ao espectador. Neste caso, a existência de tradução e tradutor não consegue ser escondida do público, garantindo a visibilidade. Se por um lado tal visibilidade promove certa consciência do público-espectador acerca da presença do estrangeiro (pelo menos em termos linguísticos, que é o que aqui nos interessa) e da mediação interpretativa, por outro, acaba por produzir avaliações e julgamentos acerca do trabalho de um tradutor a cuja identidade não se tem acesso, independentemente do conhecimento que se tem sobre a atividade tradutória para legendas e da fluência e experiência no idioma estrangeiro. Como muito bem sintetizou Nornes (1999, p. 17), "todos nós, vez ou outra, saímos do cinema querendo matar o tradutor. Motivo: Assassinato do filme por legenda "incompetente"". A despeito das tão frequentes críticas que o desconhecido (já que seu nome dificilmente é anunciado) mas presente tradutor para legendas recebe do público, quando se tem acesso ao processo de confecção das legendas para um filme, nota-se que ele é mais complexo do que pode parecer ao espectador. A legendação de um filme passa por diversas interferências e, na maioria dos casos, a tradução proposta pelo tradutor recebe alterações por parte das empresas, que não o consultam nem pedem sua anuência para fazê-las.

Tamanha e inevitável visibilidade da tradução não é característica marcada de traduções em geral. Venuti (1986), ao tratar da invisibilidade do tradutor, trouxe à explicitude teórica o fato de que os tradutores praticamente desaparecem para o leitor na domesticação excessiva dos textos que traduzem. Muitas vezes, quando o leitor lê um livro traduzido, a exemplo de "Abril despedaçado", de Ismail Kadaré, não percebe que está lendo uma tradução. No caso aqui exemplificado pode ficar ainda mais patente para o leitor a ideia de que se trata de obra nacional brasileira, uma vez que há um filme homônimo ${ }^{5}$ brasileiro, baseado na obra literária estrangeira. O leitor tem a falsa impressão de que os escritores escrevem em todas as línguas do mundo ou, no mínimo, na sua. Dito assim diretamente pode parecer absurdo, mas essa é uma impressão não consciente, que pode estar relacionada ao fato de que os textos verbais escritos não apresentam o original junto com a sua tradução e frequentemente são domesticados, de modo a que o estrangeiro se torne um tanto opaco, velado ou apagado.

Sob a ótica do cinema, as legendas comumente não desempenham um papel integrante da criação e realização da obra. Isso decorre do fato de que a legenda é material dispensável ao filme em seu ambiente de origem, a não ser que esta faça parte dele, como, por exemplo, exibição de datas, indicação de locais, os intertítulos narrativos, sendo inseridos deliberada e propositalmente. Há também a opção de cineastas, a exemplo de Peter Greenaway, que se utilizam da legenda como elemento de sua criação artística, como no filme "A Última Tempestade/Prospero's Book" (1991). Entretanto, a legenda, como uma das traduções potenciais, pode se tornar indispensável à disseminação da obra em contextos que ultrapassam, pelo menos, as fronteiras da língua de produção. E, uma vez existente, ela passa, aos olhos do espectador, a fazer parte da obra. Para ele, a legenda é tanto um elemento de acesso e compreensão do audiovisual quanto qualquer outra linguagem que constitui a criação do texto (ARAGÃO, 2006).

Antes de imergir na atividade de legendação e suas vicissitudes, é importante ressaltar que o legendador não traduz apenas da linguagem verbal oral para a escrita e que ele, pos-

5 O homônimo aqui se refere ao título da obra literária traduzida (KADARÉ, 2001) e ao título da obra fílmica (ABRIL DESPEDAÇADO, 2001). 
sivelmente, sequer tenha acesso à parcela oral do filme quando da realização da tradução. As empresas de tradução, ao encaminhar material para o tradutor, enviam a transcrição completa ou parcial dos textos do filme e os não falados estão incluídos. Assim, quando o tradutor faz a tradução, traduz também o texto verbal não falado que faz parte da obra fílmica. Um dos grandes desafios do tradutor é condensar, em determinados espaço e tempo disponíveis, as informações apresentadas pelos textos falado e escrito do filme. A legenda, seguindo suas próprias restrições e normas (que são privadas), adapta-se ao filme e não o contrário. O texto audiovisual envolve verbo, imagem e movimento, e esses componentes se entremeiam de tal modo, que pensar em cada um deles isoladamente pode obstruir a interpretação e então a tradução (ZABALBEASCOA, 2008). Eles têm o objetivo de produzir sentidos, mensagens, e é preciso pensar nos diversos elementos que cercam tais sentidos e fazem parte da sua composição para traduzi-los.

Considerando a complexa composicionalidade do texto audiovisual, Zabalbeascoa (2008, p. 24) sugere quatro conjuntos de signos que se combinam. Tais elementos também são explorados por Delabastita (1990) e Díaz Cintas (2008):

1) Áudio-verbal: palavras que são ouvidas;

2) Áudio-não verbal: todos os outros sons /música e efeitos especiais;

3) Visual-verbal: palavras que são lidas;

4) Visual-não verbal: todos os outros signos visuais /imagem /gestos.

Zabalbeascoa destaca ainda que, dependendo da natureza do filme, um dos componentes pode estar mais ou menos presente, e é importante que o tradutor esteja ciente dos tipos de combinações que podem ser estabelecidos entre palavras, imagens e outros elementos textuais que fazem parte do texto e qual a sua importância para a tradução. Segundo Díaz Cintas (2004), a princípio todas as dimensões podem ter igual importância, mas, no caso dos filmes, parece ser a visual-não verbal, a imagem, a mais central. Santaella (2004, p. 53), ao falar sobre a relação entre imagem e texto, destaca a complementaridade entre elas, já que as mensagens são organizadas de tal forma, que o imagético seja capaz de transmitir o máximo possível de informações e que o verbal endosse o que já foi elaborado visualmente ou acrescente informações específicas que a imagem não consegue materializar. Na linguagem fílmica, ainda há a presença do som, peça fundamental na ambientação e que complementa a construção da mensagem ao espectador.

Mesmo com tamanha complexidade constitutiva devida à combinação de diferentes linguagens e embora o trabalho de tradução com vistas à criação de legendas sofra alterações quanto aos procedimentos, programas utilizados e algumas instruções, de modo geral as orientações, as etapas e agentes envolvidos na tradução se assemelham. A descrição que aqui se apresenta é relativa à atuação do tradutor freelancer na SDI Media (responsável pela legendação do filme The Woods, objeto da análise realizada por Staudinger ${ }^{6}$ ). Quanto às etapas e prazos para se chegar ao produto final da legenda, ocorre o seguinte:

a) O tradutor recebe um e-mail do seu supervisor, consultando-o a respeito da possibilidade de realização do trabalho em prazo determinado.

b) Confirmada a disponibilidade, o supervisor envia o arquivo com as legendas transcritas, reiterando o prazo de envio do material para o setor técnico e de controle de qualidade (CQ).

6 Para acesso ao detalhamento da pesquisa e suas considerações, consultar Staudinger (2010). 
c) Recebido o material, o tradutor precisa acessar a página FTP para baixar o vídeo do filme - que pode levar 2 horas, dependendo do tamanho e da quantidade de arquivos - e começar as suas pesquisas relacionadas ao material a ser traduzido.

d) Nessas condições, o tradutor tem o prazo médio de 14 horas (incluindo toda a madrugada e uma manhã) para realizar o trabalho ${ }^{7}$. A situação é mais ou menos esta: a supervisão fica em Los Angeles, e a diferença do fuso horário é de 6 horas a mais no Brasil. Normalmente, a distribuição é feita no período da tarde, o que significa, na melhor das hipóteses, início da noite no Brasil. Geralmente o prazo de envio da legenda é o início da manhã do dia seguinte, no horário de Los Angeles, para arquivos com 40 minutos (aproximadamente 700 legendas no caso das séries de televisão).

e) Em alguns casos, quando a empresa recebe material excessivamente extenso para ser traduzido em um prazo muito curto, os supervisores fracionam o texto, dividindo a tradução entre diversos tradutores. Ou seja, há a possibilidade de o tradutor receber uma porção textual que se situa no meio ou no final da obra, sem que possa ter acesso à íntegra do material.

A descrição acima demonstra a rotina intensa, exaustiva e nunca planejada - posto não se saber quando se vai receber material para tradução - que é desencadeada pelo processo estressante que envolve a realização do trabalho. Muitas vezes, o cumprimento do prazo prejudica e/ou impede a revisão das legendas. Além disso, durante o processo de legendação, o tradutor precisa ter em mente as normas técnicas que delimitam o seu trabalho, das quais se destacam:

a) Não utilizar mais de 2 linhas com 38 caracteres cada - incluindo espaços e pontuações;

b) Não ultrapassar o limite de caracteres indicado em cada legenda - há a permissão para superar em $20 \%$ o número de caracteres indicado, que somente deve ser utilizada em casos especiais, isto é, evitada ao máximo;

c) Respeitar o espaço disponível em cada legenda, considerando que ele está diretamente relacionado com o tempo da fala original, tempo do personagem em cena;

d) Evitar abreviações;

e) Não traduzir nomes próprios dos personagens e os títulos;

f) Evitar ao máximo o uso de palavrões.

O resultado da tradução realizada pode não coincidir - e frequentemente não coincide - com o que o espectador vê na tela ao acessar a obra audiovisual, já que há um controle de qualidade (CQ) que tem ampla autonomia para alterar a tradução, sem a necessidade de consultar ou comunicar o tradutor cuja identidade frequentemente não é revelada ou sequer considerada.

Como se vai demonstrar com alguns exemplos a seguir, a análise das legendas produzidas pelo tradutor e das alterações feitas pelo profissional do CQ da empresa de legendação permite a percepção da interferência sobre a atuação do tradutor, associada a perspectivas bastante particulares - tanto em relação ao filme quanto ao ambiente e às condições da tradução - e às limitações técnicas. Pode-se dizer que o trabalho do CQ é

7 Consta do texto da dissertação de Staudinger, equivocadamente, o prazo de 18 horas. O cálculo mais adequado, considerando as diferenças de fuso horário, indica um tempo máximo de 14 horas para a tradução. 
de revisão, e o legendador é quem faz a tradução propriamente dita; entretanto, é o CQ que tem autorização inclusive para desrespeitar parcialmente as normas, se assim considerar necessário. Desse modo, o olhar e a atuação que o legendador tem sobre a obra está sujeito a limitações que ultrapassam a natureza técnica da atividade e o acesso à obra completa, já que o revisor, além de poder acessar a obra audiovisual, goza de privilégios e permissões para alterar as legendas, que o legendador não possui.

A obra The Woods, suspense que se passa em um internato para mulheres no ano de 1965, por exemplo, tem 703 legendas, em $91 \mathrm{~min}$ de filme. Houve 82 alterações e/ou eliminações feitas pelo CQ da empresa SDI Media em relação à proposta da tradutora. Um exemplo de alteração foi a tradução de "Fire-Crotch", apelido da protagonista, que é uma menina ruiva. A opção da tradutora, respeitando as normas de extensão e o não uso de palavras de baixo calão, foi "Tocha". O CQ alterou a tradução para "Cabelinhos de Fogo", a despeito da extensão e da delicadeza da expressão em português em comparação ao apelido original, que faz menção aos pelos pubianos da personagem.

Um outro exemplo que se pode mencionar é a tradução de spanking no enunciado "And then what? A spanking?". A proposta de tradução da legendadora foi "E depois? Vão me espancar?", mas o que apareceu na tradução para o DVD foi "E depois? Vão me bater?". Nota-se que a mudança pode criar no espectador-leitor a impressão de que algo foi roubado na tradução, já que as palavras spanking e espancar possuem conteúdo semântico bastante próximo, tratando-se de cognatas. Além disso, a força expressa por meio da palavra espancar é muito maior do que por bater, tanto no inglês quanto no português. $\mathrm{O}$ ambiente do filme: internato exclusivo para moças, tendo apenas professoras no quadro docente (poucos personagens masculinos na trama) faz com que a palavra seja associada à rigidez das regras de conduta comum nos colégios internos, onde o castigo aos estudantes geralmente vinha associado à violência física. No caso da tradução para audiovisual, o espectador, quando focado na leitura das legendas, absorve algumas palavras isoladas do áudio (normalmente as que chamam atenção porque ele conhece a tradução literal) e, se não as lê na legenda, determina ali a incompetência do tradutor.

Como se pode observar, a tradução para legendas não é apenas um registro limitado tecnicamente do que é falado na obra audiovisual. Trata-se de um processo que passa pelo filtro interpretativo dos agentes da tradução. E tal filtro perpassa a interpretação do espectador-leitor da obra para muito além das nuanças relativas às escolhas terminológicas. Além de a tradução garantir a sobrevivência de um texto, o que significa que, sem ela, muitos escritos estariam perdidos e junto deles o conhecimento e um conjunto de desejos, ela pode, ainda, ser a abertura por meio da qual os processos de produção de sentidos são possibilitados, como ocorre com a legendação.

Quando Nord escreveu sobre a tradução em 1997, falou que ela poderia ser analisada a partir de uma dupla perspectiva: a relação entre o texto traduzido e seus leitores e a relação entre texto traduzido e o seu original. Com a legendação, essas relações não podem ser avaliadas isoladamente, pois a presença da imagem e do áudio original une, quase que intrinsecamente, os três componentes: texto original, texto traduzido e leitor/espectador. Além do mais, a imagem que a legenda acompanha, controla a viagem criativa do tradutor, pois imagem e texto precisam fazer sentido, respeitando o trabalho dos autores do material original.

Pode-se dizer que os espectadores compreendem a obra fílmica através dos olhos do tradutor, o que o torna figura essencial para a compreensão da mensagem. E, a despeito da popularidade e das severas críticas que a legendação sofre, ela é necessária (salvo nos 
casos em que se opta por dublagem) quando o espectador não conhece a língua falada no filme. E é em razão dessa popularidade e necessidade que Daminelli desenvolveu sua pesquisa de doutorado com vistas à aproximação dos sujeitos aos processos de leitura, a respeito da qual trataremos na próxima seção deste artigo.

\section{Obras estrangeiras legendadas no ensino da leitura em língua portuguesa como L1}

O segundo estudo de que tratamos neste artigo é a tese de doutorado de Daminelli, intitulada "Filmes legendados: perspectiva para o ensino de leitura em língua materna", defendida em 2014, também na Pós-Graduação em Estudos da Tradução da UFSC, sob a orientação da primeira autora. A pesquisa trata do ensino de leitura em contexto de dificuldade de aprendizagem e baixo desempenho escolar dos estudantes, propondo e implementando, experimentalmente, projeto de ensino de leitura a partir do trabalho com textos audiovisuais estrangeiros legendados 9 .

A implementação do projeto de docência foi realizada em escola pública estadual de educação básica de um pequeno município do interior do sul de Santa Catarina, com estudantes concluintes do ensino fundamental de 8 anos (período de transição para 9 anos ${ }^{10}$ ), que tinham idade entre 11 e 16 anos. O público-alvo do estudo foi considerado pela escola como estudantes com baixo potencial de aprendizagem e, por isso, havia sido separado das e nas salas de aula, para constituição de grupo especial, com vistas a promover uma espécie de trabalho diferenciado daquele realizado em sala de aula regular.

Havia duas turmas de estudantes em situação de conclusão do ensino fundamental de 8 anos na escola, uma matutina e outra vespertina. Dessas turmas, ainda na $6^{\mathrm{a}}$ série, 21 estudantes foram separados para constituir o grupo com o qual a escola realizaria trabalho diferenciado de ensino. Os demais estudantes, 35, permaneceram e suas turmas de origem. Depois de ter tentado trabalhar com os estudantes separadamente, a escola reavaliou a situação e chegou à conclusão de que não havia sido produtiva a segmentação dos grupos. Então, os estudantes compuseram classe única, que foi subdividida em duas classes, uma matutina e outra vespertina, ficando a critério de cada estudante a escolha do turno e, consequentemente, da turma a qual passariam a se integrar ${ }^{11}$.

Estes foram os estudantes com os quais se decidiu desenvolver a pesquisa, uma vez que eles eram os que mais necessitavam não apenas de atividades de ensino que considerassem suas realidades e potenciais de aprendizagem, mas também de atenção e respeito à sua já tão precária e estigmatizada situação escolar. Assim, além de testar a hipótese teórica de estudo segundo a qual o uso de filmes legendados em sala de aula promoveria o desenvolvimento e o aprimoramento das competências em leitura, a pesquisa visou também demonstrar que os estudantes tinham plenas condições de aprendizagem, contanto que se desenvolvessem projetos de ensino coerentes, consistentes, sistematizados, bem fundamentados e voltados aos objetivos pretendidos, considerando os sujeitos-alvo da aprendizagem.

8 O texto completo da tese está disponível em: $<$ http://tede.ufsc.br/teses/PGET0221-T.pdf $>$. Acesso em 9 de abril de 2017.

9 Pesquisa aprovada pelo Comitê de Ética da Universidade Federal de Santa Catarina, conforme Parecer Consubstanciado 364.783, de 12 de agosto de 2013 (CAAE: 06999113.8.0000.0121).

10 Trata-se da última turma do ensino fundamental de 8 anos na escola em que a pesquisa foi realizada.

11 Observa-se claramente, nos movimentos dos profissionais de ensino e de gestão escolar, tentativas de oportunizar aprendizagem aos estudantes. Por mais que tenham sido frustradas algumas das ações, não se pode negar que a intenção pedagógica, social e humana tenha sido a de criar melhores condições de ensino e de aprendizagem. 
Por se tratar de pesquisa experimental (com fortes similaridades metodológicas ao ensaio clínico (GIL, 2010)), foram constituídos dois grupos de participantes: o experimental (GE) e o controle (GC), sem que fossem segmentadas as turmas durante a implementação da proposta pedagógica. Ou seja, os estudantes foram todos mantidos em suas turmas de origem, e a pesquisa foi conduzida com todos, sem que nenhuma ação ou tratamento diferente fossem executados ou adotados com qualquer um dos grupos. O que caracterizou grupo experimental e controle foi ter sido considerado pela escola estudante de baixo desempenho e dificuldade de aprendizagem (GE) ou não ter obtido tal diagnóstico (GC) ${ }^{12}$.

Esta pesquisa contemplou o uso de filmes legendados, partindo do pressuposto de que a inserção de obras cinematográficas estrangeiras legendadas no contexto escolar pode se configurar como uma perspectiva para o ensino da leitura. Dessa forma, levou-se à sala de aula a proposta de intervenção e examinou-se sua potencial abrangência no campo do ensino e aprendizagem da leitura. Portanto, o texto-base foi o texto fílmico legendado, que, da mesma forma que o texto impresso, também requer um leitor, pois nele há palavras orais e escritas, sons, movimentos, sombra e luz em combinação para a produção de sentidos e expressão de desejos. O desenho da intervenção pedagógica proposta baseou-se em pesquisas que contemplam o cinema em sala de aula, a exemplo de Xavier (2003), Napolitano (2007), Bolognini (2007), Fernandes e Callegari (2009) e Fresquet (2011).

A leitura com a qual se trabalhou na pesquisa foi a leitura do escrito (neste caso, da legenda), um escrito que não constitui texto ele mesmo, mas é parte do texto fílmico, cuja interpretação é dependente do acesso ao conjunto de linguagens que lhe é constitutivo. Lê-se, portanto, a legenda em um texto multimodal. Não necessariamente, como visto na seção anterior deste artigo, este paratexto que é lido se reveste das mais adequadas condições de produção e tem como resultado o bom e adequado uso da linguagem verbal à luz daquilo que interpreta e traduz e também à luz das características da própria língua na qual se encontra a tradução. Não por isso - embora aí possa haver restrições de natureza textual ao ensino de leitura - os textos audiovisuais legendados se mostram menos propícios ao trabalho em sala de aula e ao ensino de leitura.

Durante a intervenção, realizada pela então doutoranda em 8 encontros (de 45 a $60 \mathrm{~min}$ ) com cada classe (matutina e vespertina), foram trabalhados curtas estrangeiros legendados, selecionados respeitando-se os critérios de adequação ao objetivo da proposta de ensino, ao público-alvo ${ }^{13}$ e ao tempo (trabalhou-se sempre com textos completos, nunca com fragmentos). Os seguintes textos audiovisuais foram selecionados para o projeto de intervenção:

12 No texto da tese de Daminelli, o estudo está caracterizado como pesquisa-ação, com base nos seguintes argumentos: 1) objetiva a formação e emancipação de todos os envolvidos (estudantes, professores e pesquisadoras); 2) considera a inserção e atuação ativa da pesquisadora doutoranda no ambiente e no processo de coleta de dados, e 3) promove a colaboração entre as partes. Entretanto, uma análise mais apurada do método de investigação (segundo descrição de Gil (2010)), caracteriza a pesquisa mais adequadamente como experimental, já que, tendo determinado o objeto de estudo, seleciona as variáveis que podem influenciá-lo e define formas de controle e observação dos efeitos que as variáveis produzem sobre o objeto, segundo determinados encaminhamentos metodológicos rigorosamente delineados previamente à coleta de dados. $\mathrm{A}$ pesquisa de Daminelli apresenta ainda as seguintes propriedades essenciais à experimentação: manipulação, controle e distribuição aleatória. Quanto à proximidade ao ensaio clínico (tipo específico de experimento), o pesquisador aplica um tratamento ou uma intervenção e observa seus efeitos. Este traço também caracteriza o método de pesquisa da tese de doutoramento de Daminelli.

13 Antes de elaborar a proposta pedagógica, mapeou-se a realidade dos estudantes por meio de entrevistas com eles, seus familiares e professores e também por meio da participação na rotina escolar. 
1) "Os fantásticos livros voadores do Sr Morris Lessmore"/ "The Fantastic Flying Books of Mr. Morris Lessmore" (15min07), disponível em: <https://www.youtube.com/watch? $\mathrm{v}=\mathrm{wDkfhwRlcZw}>$;

2) "O monge e o macaco"/ "The Monk and the Monkey" (04min27), disponível em: $<$ https://www.youtube.com/watch? $\mathrm{v}=0 \mathrm{twYQY7H7nU> \text {; }}$

3) "Batman sem saída"/ "Batman Dead End" (08min04), disponível em: <https:// www.youtube.com/watch?v=E6-Agp28h6s>;

4) "A lenda do espantalho"/ "La leyenda del espantapajaros" (10min12), disponível em: $<$ https://www.youtube.com/watch?v=46ZMXOV7OhU $>14$.

A exibição e exploração dos curtas respeitou a sequência em que as obras foram apresentadas acima, pois se tomou o cuidado de, gradativamente, aumentar as dificuldades de acesso à obra via legenda. Assim, o primeiro curta trabalhado em sala de aula não tem falas nem paratexto, respondendo ao objetivo de familiarizar os estudantes - que tinham tido experiências com cinema na escola apenas nos casos de ausência de professores com o projeto proposto. O segundo ocupou este lugar, por apresentar narrativa simples, linear e acessível e poucas legendas, dada a baixa densidade verbal. O terceiro, por sua vez, embora tenha poucas legendas, exige a compreensão do escrito para a construção de uma representação mental adequada do texto, já que os estudantes não tinham conhecimento suficiente nem experiência em língua inglesa e também porque se trata de narrativa não linear, com desfecho não previsível. A despeito da possível dificuldade de acesso dos estudantes à obra, optou-se por selecioná-la, por causa das personagens e da temática de grande interesse dos estudantes. Por fim, o quarto curta é o de maior densidade verbal entre todos os selecionados, o que exige maior competência leitora para acompanhar o desenrolar da trama.

Para desenvolver as atividades, foram utilizados os seguintes instrumentos: questões de acesso e compreensão da obra, devolutiva e protocolos verbais retrospectivos em grupo, em atividades realizadas antes, durante e depois da exibição dos curtas, sempre ocorridas no auditório da escola. Toda a intervenção passou por pilotagem prévia à atuação em sala de aula/auditório, o que implicou ajustes e aprimoramentos da proposta. Os estudantes foram sempre solicitados a responder oralmente ou por escrito e em atividades com o grande grupo. Por isso, para ter acesso aos registros a fim de analisá-los, com a anuência dos estudantes, as aulas foram filmadas.

Tendo esclarecido o objeto e o método de investigação, há que ponderar a respeito do porquê de se ter selecionado obras audiovisuais estrangeiras para fomentar o ensino de leitura em língua portuguesa, ou seja, na língua dos estudantes. Primeiro, para além das competências (meta)cognitivas, linguísticas, discursivas e procedurais implicadas na leitura (SOUZA, 2012), consideramos que, para aprender a ler, o estudante deve estar envolvido no processo, sentindo-se motivado e tendo interesse naquilo que se propõe como atividade de ensino. Não se pode desconsiderar o contexto no qual o projeto foi apresentado. Os estudantes-alvo estavam em vias de concluir o ensino fundamental e muitos deles sequer tinham alcançado nível básico ou pleno de alfabetização. Além disso, a experiência escolar e os sucessivos insucessos de desempenho acabaram por desmotivar os estudantes, que já se consideravam incapazes de aprendizagem. Nesta situação, portanto, a consideração da afetividade e da motivação ganha contornos ainda mais relevantes.

14 Todos os links foram acessados em 09 de abril de 2017 e encontravam-se ativos e disponíveis. 
Nessa linha, segundo Thums (1999), a aprendizagem é resultado também da soma de aspectos dentre os quais a afetividade é central. Estudos na área da leitura propõem práticas pedagógicas cujos olhares se voltem à leitura como um ato fruto de desejo. Souza (2012) afirma que, nos ambientes escolares, não se lê apenas para aprender conteúdos, lê-se também e simplesmente porque se quer ler, porque ler pode ser prazeroso, pode proporcionar momentos de lazer, de encantamento, de fruição.

Assim, para construir um contexto de aprendizagem mediante interação, o estudante deve estar plenamente envolvido no processo de ensino e aprendizagem. Para isso, consideraram-se neste estudo aspectos como as características dos estudantes, seus conhecimentos prévios relativos à leitura, a capacidade (meta)cognitiva e metalinguística, os fatores motivacionais, o nível de desenvolvimento da linguagem, para que, de fato, houvesse condições de envolvimento com a atividade proposta. Sabe-se que não há aprendizagem sem envolvimento. Tampouco, haverá aceitação, por parte do estudante, do que é proposto, se o mesmo não estiver envolvido com o objeto em questão: neste caso, a leitura.

Defende-se que o uso de filmes legendados poderá contribuir significativamente para o aprimoramento da leitura (DAMINELLI, 2010), uma vez que quanto mais exposto estiver o estudante à escrita, seja impressa no livro ou sobreposta à imagem por meio da legenda, mais próximo estará de poder se tornar um leitor proficiente. Tal afirmativa se pauta no fato de que as legendas são paratextos (elementos constituintes da obra fílmica) e, dessa forma, são parte de um texto: o fílmico. Se os estudantes têm acesso ao texto fílmico legendado, o entendimento do mesmo exigirá a leitura das legendas, e, se isso ocorrer, as habilidades leitoras poderão se desenvolver paralelamente ao ato de assistir ao filme.

Pensando na relação entre cinema e ensino, o uso de obras cinematográficas estrangeiras, considerando a riqueza da linguagem sonora e visual que constitui os filmes, converte-se em um recurso no processo de ensino à leitura, uma vez que assistir a um filme legendado implica ler e realizar atividades simultâneas complexas, como processar as imagens em movimento, os sons e as legendas, em tempo previamente definido (SOUZA; RESENDE; FREESE; DAMINELLI, 2013). Segundo estes autores, o acesso à obra, a partir da leitura do paratexto e de todo o conjunto que compõe o texto fílmico, exige empenho cognitivo do leitor, no que diz respeito à produção de sentido. Se há grande demanda de processamento em razão do complexo conjunto de linguagens que constitui a linguagem fílmica - complexidade aumentada com a inserção da legenda -, há, em contrapartida, a familiaridade com o audiovisual, a redundância informativa por meio da exposição de imagens vívidas e acessíveis mesmo ao não leitor.

Levando em consideração o contexto de ensino e aprendizagem de sala de aula, Ruddell e Unrau (1994) discorrem acerca de três agentes envolvidos no processo: o leitor, o professor e o texto. O leitor, neste caso, é o estudante com suas experiências, conhecimentos, crenças, expectativas, perpassadas pelas condições afetivas e cognitivas. Já o professor, que também é leitor, mas não é o sujeito-alvo das ações de ensino com vistas à aprendizagem, é coparticipante da produção de sentidos de um texto em sala de aula por meio da atividade de leitura. Cabe a ele planificar, sistematizar e implementar estratégias instrucionais, a fim de que objetivos de ensino tenham chance de ser alcançados. Por fim, o texto constitui o terceiro componente do modelo apresentado pelos autores no que tange à negociação de sentidos. Sem texto, em determinado contexto, não há leitura. Essa negociação de sentido acontece quando as ações pedagógicas mobilizam o engajamento 
dos estudantes em um processo cooperativo. Neste processo, não é função do professor fornecer as respostas definitivas e/ou produzir os sentidos, mas criar condições para que os estudantes possam construí-los.

Os resultados obtidos com a implementação da proposta pedagógica acima descrita - que teve duração de apenas 4 semanas - foram surpreendentes quanto à evolução observada não apenas no desempenho em leitura dos estudantes, mas também no seu empenho e envolvimento com as atividades para além do projeto que se estava desenvolvendo com eles. Vejamos como se desenrolaram os encontros e como os movimentos dos estudantes foram mudando rapidamente frente à proposta apresentada. Os resultados serão apresentados de modo sucinto e considerando as duas turmas conjuntamente ${ }^{15}$.

No primeiro encontro, os participantes estavam tímidos e se mostravam receosos. Foram pouco participativos, quando solicitados a responder oralmente. No segundo, quando foi retomado o primeiro curta, já pareciam mais à vontade e assistiram à exibição com atenção. Grande parte dos participantes demonstrou empenho na atividade de devolutiva. Entretanto, no protocolo verbal (atividade de natureza oral e coletiva), as manifestações foram mínimas. A análise das respostas obtidas revelou que as tarefas propostas haviam sido compreendidas; entretanto, a produção de sentidos se mostrou bastante insuficiente e distante do esperado quanto ao acesso à obra.

Os dados referentes ao segundo curta não foram melhores do que os do primeiro, se se considerar que houve a inserção da parcela escrita, por se tratar de obra na qual a linguagem verbal aparece. Tendo sido o primeiro curta legendado, ofereceu mais dificuldades à produção de sentido que o primeiro curta exibido. O contato com texto fílmico legendado parece ter provocado certa aflição e gerou desempenho insuficiente, mesmo entre os estudantes do GC. Além do impacto causado pela legenda e da baixa competência leitora, é possível que um dos fatores responsáveis pela insuficiência de desempenho esteja ligado à qualidade da legenda proposta. Destaca-se que os curtas exibidos são de acesso aberto ao público e que as legendas produzidas não necessariamente foram fruto de trabalho de tradutor profissional ou passaram por revisão e controle de qualidade. No que se refere à participação oral, houve uma melhora significativa. Eles participaram ativamente da atividade que consistia na ativação do conhecimento prévio acerca do assunto. Ao analisar os dados referentes ao protocolo verbal, verificaram-se 63 manifestações, ou seja, os participantes demonstraram mais segurança e interesse.

Notou-se que, entre o trabalho com o segundo e o terceiro curta, alguns participantes começaram a frequentar mais a biblioteca voluntariamente e pedir orientação e indicação de leituras à pesquisadora, que à época era professora da escola, mas estava atuando na biblioteca (por readaptação). Após a primeira exibição de Batman sem saída, ocorreram dois fatos que merecem especial destaque. Um dos estudantes - que estava entre os mais desinteressados nos estudos, segundo a escola - foi até a biblioteca à procura de livros para leitura. Além disso, ocorreu de os estudantes do vespertino se deslocarem em grupo para o auditório, antes mesmo do horário combinado e durante o intervalo de aulas - momento em que eles têm liberdade para dispor do tempo e descansar das aulas -, a fim de reservar o melhor espaço para participar das atividades e assistir à obra. Durante a exibição do curta, alguns participantes, para não perderem nenhuma informação, chegaram a fazer anotações nas suas carteiras, já que naquele momento só dispunham de lápis - o material para anotação foi entregue depois. Foi visível a preocupação do grupo em demons-

15 Os dados completos podem ser acessados em Daminelli (2014). 
trar um bom desempenho. Solicitaram explicações, debateram, retomaram as respostas, modificaram, acrescentaram novas informações. Estavam totalmente familiarizados e integrados à atividade. Fizeram comentários positivos e, principalmente, pertinentes ao assunto do curta. Pode-se, portanto, afirmar que os participantes se aproximaram de modo sensivelmente mais adequado e coerente da produção de sentido.

Por fim, o quarto curta exigiu ainda mais atenção dos participantes à legenda. Os roteiros de acesso à compreensão da obra foram elaborados de modo a que as respostas de localização e integração de informações específicas, somadas às respostas abertas, sinalizassem o acesso à obra. $\mathrm{O}$ grupo participou ativa e positivamente, respondendo as questões orais utilizadas para ativar o conhecimento prévio. $\mathrm{O}$ debate foi bastante produtivo e intenso, uma vez que o personagem da obra era um espantalho. Alguns participantes se manifestaram dizendo que as famílias tinham ainda o hábito de colocar, nos quintais das casas, espantalhos ${ }^{16}$. Ao responderem as questões escritas, observou-se que os participantes demonstraram mais agilidade, organização, envolvimento, empolgação e segurança. No último encontro, após segunda exibição, antes da devolutiva, os estudantes, tanto do turno matutino quanto do vespertino, pediram a palavra, solicitando que não encerrássemos as atividades com os curtas. Neste momento, foram comunicados de que assistiriam a mais um filme, entretanto não seria curta-metragem, tampouco seria na Escola: iriam ao cinema.

Esta atividade foi prevista para o encerramento do projeto com estudantes - encerramento no que diz respeito ao estudo de doutoramento, não no que diz respeito às atividades junto à escola. Como boa parte deles nunca havia estado em um cinema, o grupo foi levado para assistir a um longa metragem primeiro em um cineclube de uma cidade próxima - pois havia alguns impeditivos para ir ao cinema, que fica mais distante, naquele momento; depois eles foram levados ao cinema de um shopping, também em uma cidade vizinha, mas bastante mais distante da escola.

O desempenho dos participantes no último curta foi extraordinário. Somente três estudantes, de todo o grupo, não tiveram êxito. O protocolo verbal corroborou a afirmação de que estavam, em relação ao primeiro curta, muito mais participativos. A análise do protocolo possibilitou ainda a constatação de que os participantes estabeleceram relação intertextual entre $O$ monge e o macaco (segundo curta) e $A$ lenda do espantalho (quarto curta).

Nesta proposta, o texto fílmico assumiu um papel de importância inegável no processo de ensino e aprendizagem da leitura, especialmente no que diz respeito ao nível de letramento dos participantes. Os estudantes parecem ter compreendido o trabalho proposto não como um conjunto de atividades desprovido de propósito e distante dos seus desejos, mas como algo que proporcionou a eles prazer e envolvimento. Assim, esta pesquisa, mesmo levando para a sala de aula um texto que não foi produzido com fins pedagógicos (como ocorre com a maior parte dos textos), conseguiu, deslocando os curtas de seus espaços, manter a função e os propósitos do cinema.

Durante o desenvolvimento da intervenção pedagógica, observou-se que o GC se diferenciou do GE no que diz respeito à proficiência em leitura. Os dados demonstram maior fragilidade dos participantes do GE quanto aos processos e produtos da compreensão das obras legendadas exploradas em sala. Entretanto, ao longo da implementação da proposta, foi possível perceber que os participantes do GE conseguiram avançar positivamente em relação ao enfrentamento das atividades, familiaridade, produtividade

16 A maior parte dos estudantes vivia na zona rural. 
e relevância dos apontamentos que faziam. Mesmo que alguns estudantes não tenham alcançado desempenho satisfatório - o que é bastante natural, já que a intervenção durou apenas quatro semanas -, não houve caso de estagnação ou demonstração de restrição de potencial de aprendizagem.

Os resultados possibilitam a conclusão de que a legenda interfere positivamente na produção de sentidos de obras cinematográficas estrangeiras, uma vez que o participante-espectador, a partir da implementação da proposta pedagógica, tornou-se um leitor-espectador diferente, que olha, ouve, lê, espreita, procura sentidos, submete à obra à sua análise. E mais importante: os estudantes do GE demonstraram boa condição de aprendizagem da leitura, mesmo estando no final do ensino fundamental e mesmo possuindo um histórico de insucesso escolar. A partir do trabalho com os curtas, percebeu-se que foram surgindo leitores que deixavam visíveis traços de leitura proficiente. Para Kleiman (2008, p.76), “a característica mais saliente de um leitor proficiente é sua flexibilidade na leitura. Ele não tem apenas um procedimento para chegar aonde ele quer, ele tem vários possíveis, e se um não der certo, outros serão ensaiados".

Os participantes, à medida que estavam familiarizados com as atividades, demonstravam mais habilidade para ler as legendas e integrá-las à obra. É importante enfatizar que quando nos referimos à habilidade, não estamos defendendo a ideia de que é a habilidade leitora (ou o conjunto de habilidades) unicamente que possibilita a produção de sentido. Entretanto, ao considerar o perfil dos participantes, a ampliação das habilidades leitoras favoreceu a compreensão, uma vez que eles passaram a dar conta da leitura das legendas e que isso melhorou significativamente o desempenho em produção de sentidos coerentes e relevantes.

Como já mencionado anteriormente, todos os estudantes, depois de concluída a intervenção pedagógica na escola, foram convidados a assistir a um longa metragem legendado, de escolha deles, em um cineclube de uma cidade próxima àquela onde eles moravam e onde foi realizada a pesquisa. Eles escolheram, com euforia e radiantes de desejo, "Amanhecer - parte 1", quarto filme de "A saga do crepúsculo". Após a exibição do filme, houve uma sessão de debates da qual eles participaram ativamente, demonstrando terem compreendido a obra e relacionando-a a obras anteriores da mesma saga.

Um ano e meio depois de concluído o trabalho com os estudantes e de tê-los levado ao cineclube, foi possível realizar o plano - bastante mais complexo e dispendioso - de levar todo o grupo ao cinema. Desta vez, não houve escolha do filme senão dentro das possibilidades daqueles que estavam em cartaz. Assistiu-se ao "Malévola", também legendado. Acidentalmente, por uma falha da equipe de profissionais do cinema ao qual fomos, os estudantes foram levados à sala errada, onde começou a exibição da obra dublada "A culpa é das estrelas", que fez grande sucesso entre o público jovem. Ao contrário do que se poderia imaginar - que eles desejassem permanecer para assistir ao popular "A culpa é das estrelas" -, todos começaram a se manifestar, fazendo corrente de recado dentro da sala de cinema, solicitando mudar de sala para assistir a "Malévola", já que este era o combinado. Assim foi feito. E eles assistiram a todo o filme, muito atentos, e voltaram para casa discutindo a obra e empolgados com o evento e com que havia sido proposto e proporcionado a eles. Na viagem de volta para casa, em coro, os estudantes diziam "Queremos mais! Queremos mais!".

Como visto, o uso de obras cinematográficas estrangeiras, quando aliado a propostas de ensino cujo propósito está em torno do ensino da leitura, caminha para a formação de um estudante-espectador-leitor ativo. E, para tal, o estudante analisa, interpreta os textos 
fílmicos, integra a recepção da obra ao seu mundo interior, conferindo sentidos ao texto, aprimorando a prática da leitura. Com base nessa constatação, o uso de obras cinematográficas estrangeiras carrega consigo o potencial de contribuir para o ensino da leitura, uma vez que, consequentemente, leva o leitor-espectador, por meio da leitura, da análise fílmica, do olhar crítico, do conhecimento prévio, da retomada à produção de sentidos.

\section{Considerações finais}

As pesquisas de Staudinger (2010) e Daminelli (2014), sucintamente apresentadas aqui, possibilitam-nos pensar a respeito das potências da legendação para além de suas vicissitudes e complexidades, considerando a natureza desta tradução à luz de seus processos e agentes, e também possibilidades de circulação de obras audiovisuais legendadas, que transbordam o aspecto criativo e ficcional do cinema e, ainda, nos casos em que tais obras são selecionadas para projetos de ensino de línguas, vão além dos espaços do ensino de línguas estrangeiras. Apresentamos, assim, experiência bem-sucedida, fruto de pesquisa de natureza experimental, com o emprego de audiovisuais estrangeiros legendados para fomentar, instigar a aprendizagem da leitura em L1, por meio da aproximação dos aprendizes aos espaços de interpretação dos quais a escrita participa.

Esta pesquisa poderá proporcionar aos professores de Língua Portuguesa não uma receita, mas meios, potencialidades, para levar os filmes para a sala de aula, a fim de que professores e estudantes alcancem seus objetivos: o de ensinar e o de aprender - no caso aqui exemplificado, aprender a ler. É uma necessidade que o estudante interaja com os diferentes tipos de textos que circulam no meio social. Entretanto, antes de tudo, é necessário que se aprenda a ler de fato, pois o que se constata é que, mesmo aqueles que frequentam a escola, apresentam desempenho em leitura insuficiente para autonomamente produzir sentidos a partir do escrito. Por fim, com o intuito de que as ponderações não cessem aqui, destacamos as palavras de Bellenger acerca do prazer que a leitura pode proporcionar (1978, p. 17):

Em que se baseia a leitura? No desejo. Esta resposta é uma opção. É tanto o resultado de uma observação como de uma intuição vivida. Ler é identificar-se com o apaixonado ou com o místico. É ser um pouco clandestino, é abolir o mundo exterior, deportar-se para uma ficção, abrir o parêntese do imaginário. Ler é muitas vezes trancar-se (no sentido próprio e figurado). É manter uma ligação através do tato, do olhar, até mesmo do ouvido (as palavras ressoam). As pessoas leem com seus corpos. Ler é também sair transformado de uma experiência de vida, é esperar alguma coisa. É um sinal de vida, um apelo, uma ocasião de amar sem a certeza de que se vai amar. Pouco a pouco o desejo desaparece sob o prazer.

\section{Referências}

ABRIL Despedaçado. Direção: Walter Salles. Brasil-França-Suíça: Imagem Filmes, 2001. DVD. Longa-metragem (95 min). NTSC, son., color. Port.

A LENDA do espantalho. Direção e roteiro: Marco Besas. Espanha: Elemental Films, 2005. Curta-metragem (10min 12seg). Disponível em $<$ http://www.youtube.com/ watch?v=46ZMXOV7OhU>. Acesso em: 09 abr. 2017.

ARAGÃO, I. R. Palavras escritas: do cinema mudo ao falado.VI Encontrodos Núcleos de Pesquisa da Intercom - NP de Comunicação Visual. XXIX Congresso Brasileiro de Ciências da Comunicação - UnB. Brasília: Intercom, 2006. 
A SAGA do crepúsculo: amanhecer - parte 1. Direção: Bill Condon. Roteiro: Melissa Rosenberg e Stephenie Meyer. Estados Unidos: Paris Filmes, 2011. Longa-metragem (135min).

A ÚLTIMA Tempestade. Direção: Peter Greenaway. Inglaterra-França, 1991. Longa-metragem (129min).

BATMAN sem saída. Direção e roteiro: Sandy Collora. Estados Unidos: FanFilm, 2003. Curta-metragem (08min 04seg). Disponível em: <http://www.youtube.com/ watch?v=E6-Agp28h6s>. Acesso em: 09 abr. 2017.

BELLENGER, L. Os métodos de leitura. Trad. de Dora Flaksman. Rio de Janeiro: Zahar, 1978.

BOLOGNINI, C. Z. O Cinema na escola. Campinas: Mercado de Letras, 2007.

DAMINELLI, S. A contribuição de filmes legendados para o ensino da leitura. 2010.

Dissertação (Mestrado em Estudos da Tradução) - Pós-Graduação em Estudos da Tradução, Universidade Federal de Santa Catarina, Florianópolis.

. Filmes legendados: perspectiva para o ensino de leitura em língua materna. 2014.

Tese (Doutorado em Estudos da Tradução) - Pós-Graduação em Estudos da Tradução,

Universidade Federal de Santa Catarina, Florianópolis.

DELABASTITA, D. Translation and the Mass Media. In: LAFEVERE, A.;

BASSNETT, S. (Eds). Translation, History \& Culture. London /New York: Pinter, 1990, p. 97-109.

DÍAZ CINTAS, J. In search of a theoretical framework for the study of audiovisual translation. In: ORERO, P. (Ed). Topics in Audiovisual Translation. Amsterdam-Philadelphia: John Benjamins, 2004, p. 21-34.

FERNANDES, G. E.; CALLEGARI, M. V. Estratégias motivacionais para aulas de espanhol. São Paulo. Companhia das Letras, 2009.

FRESQUET, A. Dossiê Cinema e Educação. Rio de Janeiro: Booklink, CINEAD, 2011.

GIL, A. C. Como elaborar projetos de pesquisa. 5. ed. São Paulo: Atlas, 2010.

KADARÉ, I. Abril despedaçado. Trad. Bernardo Joffily. São Paulo: Companhia das Letras, 2001.

KLEIMAN, Â. Oficina de leitura: teoria e prática. 12. ed. Campinas, São Paulo: Fontes, 2008.

MALÉVOLA. Direção: Robert Stromberg. Roteiro: Linda Woolverton. Estados Unidos: Walt Disney, 2014. Longa-metragem(97min).

NAPOLITANO, M. Como usar o cinema na sala de aula. São Paulo: Contexto, 2007. NORD, C. Translating as a Purposeful Activity: Funcionalist Approaches Explained. London: St. Jerome, 1997.

NORNES, A. M. For an Abusive Subtitling. Film Quarterly, v. 52, n. 3, p. 17-34, 1999. O MONGE e macaco. Direção e roteiro: Brendan Carroll e Francesco Giroldini. Estados Unidos: Ringling College of Art and design, 2010. Curta-metragem (04min 07seg).

Disponível em: < https:/www.youtube.com/watch?v=0twYQY7H7nU > . Acesso em 09 abr. 2017.

RUDELL, Robert B.; UNRAU, Norman J. Reading as a meaning- construction process: the reader, the text, and the teacher. In: SINGER, H.; RUDELL, R. B. Theoretical models and processes of reading. Newark: IRA, Delaware, 1994, p.996-1056.

SANTAELLA, L. Semiótica aplicada. São Paulo: Pioneira Thomson Learning, 2004.

SOUZA, A. C. (Re)memória, (des)memória e aprendizagem: caminhos para se pensar a atividade de leitura: In: SOUZA, A. C.; GARCIA, W. A. da C. A produção de sentidos e o leitor: os caminhos da memória. Florianópolis: NUP/CED/UFSC, 2012. p. 27-41. 


\section{Conexão Letras}

. Leitura proficiente: processos e procedimentos. In: SOUZA, A. C.; GARCIA, W.

A. da C. A produção de sentidos e o leitor: os caminhos da memória. Florianópolis:

NUP/CED/UFSC, 2012. p. 63-79.

. RESENDE, N. R. FREESE, N. A. DAMINELLI, S. A compreensão do cinema

estrangeiro legendado e a competência em leitura. Raído, v. 7, n. 13, p. 139-159, 2013.

STAUDINGER, F. A (in)visibilidade do tradutor na legendação: a tradução do filme 'The Woods'. 2010. Dissertação (Mestrado em Estudos da Tradução) - Pós-Graduação em Estudos da Tradução, Universidade Federal de Santa Catarina, Florianópolis.

THE FANTASTIC Flying Books of Mr. Morris Lessmore. Direção e roteiro: William Joyce e Brandon Oldenburg. Produção: Iddo Lampton Enochs Jr., Trish FarnsworthSmith, Alissa M. Kantrow. Estados Unidos: MoonbotStudios, 2011. Curta-metragem (15min 07seg). Disponível em: <https://www.youtube.com/watch?v=wDkfhwRlcZw $>$. Acesso em: 09 abr. 2017.

THUMS, J. Educação dos sentimentos. Porto Alegre: Sulina, Ulbra, 1999.

VENUTI, L. The Translator's Invisibility. Criticism, v. XXVIII, n. 2, p.179-212, 1986. XAVIER, I. A experiência do cinema. São Paulo: Graal, 2003.

ZABALBEASCOA, P. The Nature of the Audiovisual Text and its Parameters. In: DÍAZ CINTAS, J. (Ed.). The Didactics of Audiovisual Translation.Amsterdam- Philadelphia: John Benjamins, 2008. p. 31-37.

Recebido em: 01/05/2017. Aceito em: 12/05/2017 